\title{
(c) (1) \\ Etiquetagem colaborativa nas bibliotecas: \\ o caso da Literatura
}

Patrícia de Almeida

Doutoranda em Ciência da Informação (Faculdade de Letras da Universidade de Coimbra)

http://dx.doi.org/10.1590/1981-5344/2741

Com o paradigma informacional da web 2.0, chega aos serviços de informação e documentação um conjunto de práticas provenientes da folksonomia, entre elas a atribuição de etiquetas por produtores e consumidores de recursos online. Estudos revelam que algumas bibliotecas têm já implementado um catálogo 2.0 e beneficiam da colaboração dos seus utilizadores em diversas áreas do saber, contudo escasseiam trabalhos na área da Literatura, tradicionalmente não indexada. Com o intuito de verificar se a etiquetagem colaborativa seria um fator de enriquecimento do catálogo e melhoraria o serviço prestado pelas bibliotecas nesta área do saber, realizouse um estudo de caso com obras literárias de Almeida Garrett, recorrendo-se, para tal, aos dados da plataforma LibraryThing. Confirmaram-se o predomínio de informação correta, com valor acrescentado, bem como a ocorrência de alguns dos aspetos problemáticos, referidos em investigações anteriores. Assim, defende-se uma folksonomia assistida na atribuição de etiquetas para a Literatura e conclui-se que este sistema seria vantajoso para o utilizador de um catálogo 2.0, para o profissional da informação e para a construção coletiva de conhecimento.

Palavras-chave: Folksonomia. Etiquetagem colaborativa. Bibliotecas. Literatura.

\section{Collaborative tagging in libraries: Literature as a case study}


In the informational paradigm of Web 2.0, information and documentation services deal with folksonomy practices, including collaborative tagging by producers and consumers of online resources. Studies reveal that some libraries have already implemented a 2.0 catalog and benefit from the collaboration of its users in many areas of knowledge, however researches about Literature, traditionally not indexed, are unusual. In order to verify if collaborative tagging would be a catalog enrichment factor and improve the service provided by libraries in this area of knowledge, a case study with Almeida Garrett's books was accomplished, using data of LibraryThing platform. It was confirmed the predominance of correct information with added value as well as the occurrence of some of the problematic aspects reported in previous research. Thus, it defends an assisted folksonomy in collaborative tagging to Literature and concluded that this system would be advantageous for users of a 2.0 catalog, for information professionals and for collective construction of knowledge.

Keywords: Folksonomy. Collaborative tagging. Libraries. Literature.

Recebido em 14.06.2016 Aceito em 05.03.2018

\section{Introdução}

Nos últimos anos, com o advento da web 2.0, assiste-se a uma mudança na relação entre a informação da web e o seu produtor/utilizador. Já não são necessários especialistas em linguagem de programação para editar o hipertexto e o utilizador abandona a postura passiva, assumindo um papel ativo na partilha, produção e divulgação da informação. A web tornou-se um espaço dinâmico e interativo, propício ao conteúdo colaborativo e ao nascimento de uma inteligência coletiva, onde se "acredita que ninguém sabe tudo, mas todos sabem alguma coisa e que, portanto, a união das sabedorias individuais ou de pequenos grupos poderia resultar em decisões melhores até mesmo que as tomadas por especialistas" (GOUVÊA; LOH, 2007, p. 3). Assim, defende-se que as instituições devem assumir, promover e potenciar o diálogo com os utilizadores, contemplando cada vez mais atividades de autoria partilhada (FREIXA-FONT, 2011).

Neste contexto, surgem cada vez mais plataformas abertas à participação e aos conteúdos dos seus utilizadores, com uma dimensão social e colaborativa de grande relevo para as instituições que as promovem. Fala-se de folksonomia, enquanto processo ou produto de inteligência coletiva, de etiquetagem colaborativa de conteúdos online e 
de uma consequente mudança no paradigma informacional dos serviços de informação e documentação. Como tal, as bibliotecas não podem ignorar o momento e devem tirar partido dessa inteligência coletiva, nomeadamente através dos ambientes colaborativas da web 2.0 e das práticas folksonómicas dos seus utilizadores.

Já implementada em algumas bibliotecas nos Estados Unidos da América e recomendada pela Biblioteca do Congresso (YEDID, 2013), a etiquetagem colaborativa em catálogo 2.0 tem trazido diversos proveitos para estas instituições e para quem usufrui dos seus novos serviços. Porém, este cenário não se apresenta generalizado e a literatura da ciência da informação aponta reconhecidos obstáculos na implementação de um sistema de etiquetagem colaborativa, inerentes às especificidades das práticas folksonómicas. Assim, muito provavelmente o hibridismo será - caminho do futuro, com um processo misto de etiquetagem de colaboração entre utilizador e profissional da informação e com o surgimento de uma folksonomia assistida.

Vários estudos generalistas ou centrados em áreas de saber específicas apontam os benefícios e os problemas da etiquetagem colaborativa, no entanto, em catálogos 2.0 de bibliotecas, gera-se um conjunto vazio, relativo aos documentos integrados na classe $8^{1}$, entre os quais se salientam os textos literários ficcionais, tradicionalmente não indexados através de linguagens vocabulares ${ }^{2}$. Por esta razão, algumas vezes, este tipo de documentos e outros a ele associados, nomeadamente estudos auxiliares sobre obras literárias, não é localizado nem recuperado pelos utilizadores.

Dado o interesse da Literatura, sobre a qual escasseiam trabalhos académicos no âmbito da folksonomia, propõe-se um estudo que, primeiramente, aborda a folksonomia, no que respeita aos conceitos e às implicações no atual contexto das bibliotecas, bem como o catálogo 2.0, na perspetiva do presente e do futuro, e segue com um estudo de caso sobre as obras literárias de Almeida Garrett, constantes na plataforma LibraryThing, com abordagem e análise qualitativa das etiquetas ali atribuídas. Pretende-se determinar se o catálogo das bibliotecas poderá beneficiar da cooperação dos seus utilizadores, através da etiquetagem colaborativa, também para uma área tradicionalmente não indexada; mais especificamente, aferir se a inclusão colaborativa de etiquetas em géneros literários relativos à ficção poderá enriquecer o catálogo da biblioteca e, consequentemente, melhorar o serviço de leitura prestado por esta instituição. Após a explanação da metodologia, o trabalho continua com a discussão dos resultados, onde se recorreu a alguns procedimentos característicos de métodos quantitativos, para melhor perceção dos dados obtidos. Por fim, em função dos resultados alcançados, registam-se algumas conclusões sobre as práticas folksonómicas, em especial sobre a

${ }^{1}$ Classe que compõe o sistema de Classificação Decimal Universal (CDU) e que expressa os assuntos sobre e relacionados com Língua, Linguística e Literatura.

2 Estas obras não se encontram indexadas na maioria das bibliotecas, em particular nas portuguesas, uma vez que abordam assuntos ficcionados e, como tal, não são alvo do mesmo tratamento dado às obras que referem assuntos científicos ou específicos. A introdução de estes assuntos num catálogo alfabético de assuntos poderia mesclar assuntos de natureza científica com ficção relativa ao mesmo tema. 
etiquetagem colaborativa de obras ficcionais no catálogo 2.0 das bibliotecas.

\section{Folksonomia: conceitos e implicações no atual contexto das bibliotecas}

Uma conjetura de conteúdos gerados pelos utilizadores propicia o surgimento da figura do prossumidor, amálgama linguística para o produtor e consumidor da mesma informação, e da prática da folksonomia. O termo será composto pelos elementos folk (povo) e nomos (norma) e entendido como uma espécie de taxonomia popular, livre e sem regras. O seu criador, Vander Wal (2007, s.p.) explica, claramente, que a folksonomia é criada a partir do ato de colocar uma etiqueta pela pessoa que está consumindo as informações e é o resultado da etiquetagem livre e pessoal de informações ou objetos (qualquer coisa com uma URL) para a própria recuperação. Contudo, ao longo dos anos, verifica-se a ausência de unanimidade sobre o significado deste termo, algo já sistematizado por Catarino e Baptista (2009), sendo este entendido ora como um processo de atribuição de etiquetas ora como um produto advindo dessa atribuição, com valor agregado e resultante da soma de personomias, isto é, de taxonomias individuais (CHOI; JUNG; MOON, 2014). Este estudo não pretende discutir a etimologia do vocábulo, porém reconhece que tal ideia parece contraditória, se se atender ao caráter estruturado e controlado e à organização vertical dos conceitos de uma taxonomia, pelo que compreender a folksonomia e a personomia enquanto taxonomias ocasionará algumas dúvidas ou incongruências.

Este cenário poderá ser uma consequência da utilização de outros vocábulos ou expressões para algo semelhante à folksonomia, situação relatada por Gouvêa e Loh (2007, p. 1): "Alguns termos sinônimos estão sendo utilizados tais como "tagsonomia" e "tagging" (ou "collaborative/social tagging" ou "tag generation" ou "tag/web annotation"). Outro termo que poderia ser utilizado é "thesaurus social", pois uma folksonomia utiliza termos para descrever classes". Numa leitura rápida da literatura da área, encontram-se menções a etiquetagem social, indexação social, classificação social, classificação popular, etnoclassificação, classificação distribuída, etiquetagem colaborativa, indexação cooperativa, com respetiva tradução nas diferentes línguas, sem que se perceba muito bem se aos diversos significantes corresponde o mesmo significado.

Para efeitos deste estudo, compreende-se a folksonomia enquanto conhecimento popular, por confronto à taxonomia dos serviços especializados de informação e documentação, e enquanto produto do processo coletivo de atribuição de etiquetas (tags). Opta-se pelo termo etiqueta e não descritor, uma vez que uma folksonomia implica vocabulário livre e descontrolado e este último é utilizado em vocabulários controlados; de igual modo, evitam-se ambiguidades, no sentido em que nem sempre o conteúdo da etiqueta é a descrição da informação e sim um 
qualquer tipo de relação entre informação e utilizador. Considera-se que etiqueta corresponde a uma forma livre, inserida num sistema aberto e colaborativo pelo seu utilizador, não só para descrever, mas principalmente para categorizar, organizar e recuperar informação. Rejeita-se a utilização de palavra-chave, enraizada na publicação científica, e de marcador, evitando a ambivalência entre a marca e aquele que a efetua. Nesta senda, entende-se que o ato do prosumidor de livremente atribuir etiquetas a um recurso, para categorização, organização e posterior recuperação da informação, corresponde a etiquetagem (tagging); se tal se verifica numa plataforma web aberta, onde os utilizadores contribuem com o seu conhecimento e da qual beneficiam, trata-se de etiquetagem colaborativa (collaborative tagging). Opta-se por esta fraseologia, uma vez que indexação, classificação ou tesaurus apresentam-se como vocábulos correspondentes ao trabalho de um especialista em informação, o que não é o caso, e que se deve dar realce ao procedimento colaborativo proporcionado por uma plataforma 2.0.

Esta atribuição de etiquetas não prevê qualquer controlo ou relações hierárquicas, verticais ou de nível entre conceitos, antes plena liberdade e relações horizontais num único nível, algo bem diferente dos vocabulários controlados oferecidos pelos serviços de informação e documentação. Assim, considera-se indiscutível que a etiquetagem colaborativa, enquanto atribuição de etiquetas, livre e unirelacional, constitui uma mudança de paradigma informacional. Entre os investigadores, existe a ideia generalizada de que os serviços de informação e documentação, tal como as bibliotecas, não podem ignorar o momento e devem tirar pleno partido das potencialidades da web 2.0, da inteligência coletiva e dos ambientes colaborativos, mais concretamente do conhecimento advindo de práticas folksonómicas.

Juárez Urquijo (2006) defende que a filosofia da web 2.0 pode ajudar a criar uma biblioteca pública mais ativa e comunicativa, sendo a participação do utilizador a chave para o êxito de novas iniciativas. Blattmann e Silva (2007, p. 193) asseguram que os bibliotecários precisam acompanhar a evolução tecnológica e o ambiente colaborativo em rede, falam da necessidade de ir além nos "serviços tradicionais, estáticos, assíncronos e [de] observar a interação e colaboração dos usuários" e lembram que os profissionais da informação precisam estudar e conhecer bem as tecnologias disponíveis e suas ferramentas simples, fáceis de usar, eficazes, de baixo custo e alto retorno. Chua e Goh (2010) dão conta de que a era da digitalização da informação parece ter aumentado as expectativas dos utilizadores e de que páginas da web estáticas já não são o suficiente; quando implementada em bibliotecas, a web 2.0 tem o potencial para promover a rede participativa, onde os bibliotecários e os usuários podem comunicar, colaborar e criar conteúdos. $\mathrm{Na}$ sua investigação, relatam a experiência de bibliotecas norteamericanas que promovem etiquetagem colaborativa e que incluem a 
busca por etiquetas nos seus catálogos, concluindo que a América do Norte lidera nas aplicações 2.0, face à Europa e à Ásia.

\section{Catálogo 2.0: presente e futuro}

Reconhece-se que a etiquetagem colaborativa terá a sua visibilidade e utilidade nos catálogos online das bibliotecas, um pouco à semelhança do que acontece em plataformas como Flickr³. Blattmann e Silva (2007) referem um estudo de Coyle (2007) ${ }^{4}$ sobre os impactos da web 2.0 referentes aos catálogos das bibliotecas, onde a investigadora enfatiza a necessidade de estas instituições realizarem mudanças nos seus catálogos, com o intuito de criar novos serviços aos utilizadores, apontando que a web 2.0 permite práticas sociais da informação, tais como revisões, recomendações e indexação colaborativa. Rolla (2009) salienta que os utilizadores das bibliotecas estão familiarizados com a procura na internet e têm certas expectativas sobre a busca de informação e como ela será exibida, no entanto o expectável não corresponde à forma como a informação está contida, como é descoberta e como é apresentada nos catálogos tradicionais; isto apesar de a maioria dos investigadores de folksonomias e etiquetagem apresentar uma atitude positiva em relação às mesmas e sentir que a atribuição de etiquetas melhoraria os websites e os catálogos das bibliotecas. Spiteri (2007) relata que importantes bibliotecas implementam práticas folksonómicas nos seus catálogos e páginas web e confirma a sua utilidade e imagem positiva, podendo estas servir como uma ferramenta muito poderosa e flexível para aumentar a facilidade de uso e a interatividade dos catálogos de bibliotecas públicas. A inclusão de um sistema de etiquetagem nos catálogos das bibliotecas, aberto à participação dos utilizadores, é já uma recomendação do grupo de trabalho da Biblioteca do Congresso, admitindo que se trata de uma estratégia para que os catálogos se apresentem mais moldados aos hábitos dos utilizadores e para que se melhore 0 acesso aos recursos (YEDID, 2013). Implementada a recomendação, estar-se-ia em presença de um "catálogo 2.0 ou catálogo social ou ainda o catálogo de nova geração [...] um novo modelo de catálogo que se traduz, por um lado, na reformulação das lógicas e formas de acessibilidade tradicionais" (LEITÃO, 2009, p. 128).

Spiteri (2007) defende que as práticas folksonómicas podem contribuir significativamente para os catálogos de bibliotecas públicas, permitindo que os utilizadores organizem espaços pessoais de informação, isto é, criem e organizem o seu próprio espaço de informação no catálogo. Assim, alguns estudos apontam já os proveitos de um catálogo 2.0, como é o caso de Juárez Urquijo (2006), com o relato do sistema implementado na Biblioteca Municipal de Muskiz, que facilita a visualização da

\footnotetext{
${ }^{3}$ Disponível em: <https://www.flickr.com/> . Acesso em: 5 jan. 2016.

${ }^{4}$ COYLE, K. Managing technology: the library catalog in a 2.0 world. Journal of Academic Librarianship, v. 33, n. 2, p. 289-291, mar. 2007.
} 
informação, a navegação entre conteúdos e a difusão da informação. Yunta (2009) fala da agilidade em captar novidades e da proximidade real às práticas sociais, que atribuem à folksonomia alguma vantagem perante ferramentas tradicionais de controlo de vocabulário. González (2009) aponta a exaustividade da linguagem e a representação mais consistente da informação. Gracioso (2010, p. 147) refere a precisão na recuperação da informação através de valor acrescentado, algo que ela apelida de garantia pragmática, isto é, "a soma entre a garantia semântica e de uso, ou cultural [...], em que se vincularia ao termo sugerido pelo usuário para inserção no vocabulário a descrição sobre o uso que faz deste conceito em seu contexto situacional de busca de informação". Kakali e Papatheodorou (2010) confirmam que algumas bibliotecas lançaram novos catálogos online de acesso público que incorporam marcação social e especificam que a etiquetagem colaborativa é especialmente útil para bibliotecas digitais. Segundo e Vidotti (2011, p. 89) reconhecem a mudança de paradigma e o seu contributo para a criação de uma inteligência coletiva: "A Folksonomia mudou o paradigma em relação à recuperação da informação em ambientes Web. Portanto, trata-se de um recurso rico, que contribui de forma acentuada para o fortalecimento e solidificação da Internet como plataforma para construção de informação coletiva". Leitão (2009, p. 114) afirma que a mudança de ambiente web "não pode ser ignorada pelas bibliotecas, do ponto de vista dos conteúdos em si mesmos, mas também pela possibilidade de fazer intervir os utilizadores na produção cooperativa de serviços e conteúdos", promovendo-se a perceção da construção conjunta do conhecimento. $O$ investigador defende que "o baixo custo e o processo colaborativo de produção fazem com que este seja, no momento actual, o único método que permite a indexação de quantidades verdadeiramente significativas de recursos disponíveis na Web" (LEITÃO, 2009, p. 127), uma opinião confirmada por Yedid (2013, p. 22): "Otra ventaja que resulta del uso de las folksonomías es la distribución del trabajo en ambientes en los que se manejan grandes volúmenes de información". Guedes et al. (2011, p. 54) salientam que as "práticas de indexação nos espaços sociais semânticos dotados de folksonomias revelam o poder da linguagem como meio de interação para alcançar significados de informação nos processos de organização documentária".

A utilização de conhecimento proveniente de uma inteligência coletiva não substituirá o conhecimento especializado proporcionado pelos cientistas da informação e será compreensível que se gere alguma desconfiança e desagrado nestes profissionais, em relação aos contributos dos ambientes folksonómicos. No entanto, a "literatura [...] fornece evidências que permitem afirmar que os profissionais têm vindo a evoluir desde atitudes de rejeição ou indiferença até à aceitação da importância do fenómeno e a sua integração no campo de trabalho das bibliotecas" (LEITÃO, 2009, p. 127). Convencidos dos proveitos, os profissionais das bibliotecas tentam ultrapassar os obstáculos de um processo paradoxal, pois a melhor qualidade das folksonomias transforma-se no seu maior 
defeito. O caráter livre e ilimitado da linguagem folksonómica de etiquetagem colaborativa gera o descontrolo e esta será a maior barreira à sua implementação em catálogos 2.0. González (2009) atenta que a falta de limites na etiquetagem converte-a num instrumento de dimensão desproporcional. Assim, uma ausência de organização e monitorização poderá conduzir à "bagunça informacional" (COELHO, 2015) e impedir o acesso à informação, a sua precisão e revocação, quer pela qualidade quer pela quantidade das etiquetas.

Muito embora existam reconhecidas dificuldades, será inegável que a perspetiva folksonómica é a que mais se aproxima da forma de pensar e comunicar dos utilizadores, pelo que, como caminho de futuro, uma boa parte dos investigadores aponta o hibridismo para as bibliotecas, isto é, a implementação de um processo misto de etiquetagem, com algum grau de controlo por recursos informáticos ou humanos especializados. Rolla (2009) afirma que as etiquetas geradas pelos utilizadores por si só não permitem o melhor acesso aos materiais das coleções das bibliotecas, mas podem ajudá-las a prosseguir trabalho na direção correta. Mais especificamente, as etiquetas geradas pelos utilizadores aperfeiçoam os vocabulários controlados e proporcionam um melhor acesso à informação. Esta será também a opinião de Gracioso (2010), que fala da necessidade de repensar estruturas e de instrumentalizar os processos de intermediação da informação. Segundo e Vidotti (2011, p. 103) reconhecem que o modelo folksonómico "não deve substituir os tradicionalmente utilizados, mas sim agregar mais um tipo de pesquisa e interação do usuário com o ambiente" $\mathrm{e}$, tratando-se de repositórios digitais, sugerem a implementação de uma folksonomia assistida, "um processo de apoio ao usuário, no momento de definir os termos mais adequados para as tags que referenciarão seu trabalho" (VIDOTTI, 2011, p. 91). Zubiaga et al. (2012) revelam que os utilizadores são influenciáveis pelos sistemas de sugestão de etiquetas, tendendo a selecionar etiquetas sugeridas mais do que a colocar as próprias.

Face aos proveitos apontados pelos diversos estudos, entende-se que as bibliotecas não podem deixar de usufruir dos recursos proporcionados pela web 2.0 e devem promover momentos e espaços de participação aos seus utilizadores. Defende-se a futura implementação generalizada de sistemas de criação coletiva de conhecimento, o que já é uma realidade presente em algumas bibliotecas através do catálogo 2.0, e reconhece-se que tal processo encontrará obstáculos. Desta feita, resta concordar com Rolla (2009): se permitirem que os seus utilizadores contribuam com etiquetas para seus catálogos, as bibliotecas terão de descobrir como lidar com alguns dos problemas inerentes às folksonomias. Conclui-se, então, a necessidade futura de alguma moderação nas linguagens folksonómicas de etiquetagem colaborativa. Revista a literatura, acredita-se que o caminho do hibridismo proporcionará a desejada adequação (âmbito folksonómico) e a indispensável precisão (âmbito especializado), sendo aceite como viável a inclusão de uma espécie de folksonomia assistida e a sugestão de etiquetas, como boas 
soluções para contornar o descontrolo e a falta de limites e relações, que causam estranheza aos profissionais da informação.

\section{0 caso da Literatura}

Como se observou, vários estudos apontam proveitos e problemas resultantes dos sistemas folksonómicos de etiquetagem colaborativa, quer em termos de representação do conteúdo quer na sua recuperação. Ao descontrolo e à ausência de limites e de estrutura hierárquica e multirelacional, acrescenta-se o alto grau de subjetividade do processo de etiquetagem e da intenção pessoal que preside ao ato, reconhecendo-se que, por vezes, as etiquetas revelam ausência de significado coletivo e geram imprecisão e ambiguidade. Contrapõe-se com a melhoria dos níveis de precisão e revocação; com o acréscimo em termos de garantia e validação terminológica de vocabulários controlados; com a agregação de valor à descrição tradicional, nomeadamente conteúdos secundários; com a rapidez de atualização da linguagem; com a diminuição de custos; com a possível serendipidade na pesquisa; com o surgimento de comunidades e grupos de afinidades e interesses; com a compreensão do perfil do utilizador; e com o respeito pela diversidade cultural.

Estes resultados são provenientes de estudos generalistas ou centrados em classes específicas, alvo de indexação pelos serviços de informação e documentação. No entanto, ao implementar um sistema de etiquetagem colaborativa no catálogo das bibliotecas, gera-se um conjunto vazio para os documentos ficcionados da classe 8, tradicionalmente não indexados. González (2011, p. 158 e 160) afirma que "os vocabulários controlados não são aplicáveis à maioria dos casos onde se pode usar metadados" e que "não é fácil construir e manter uma taxonomia ou uma linguagem associativa. Neste sentido as folksonomias são uma solução quando a indexação tradicional não é viável". Assim, será obrigatório colocar a hipótese de abrir a Literatura à etiquetagem colaborativa e investigar a questão: Poderá o catálogo da biblioteca beneficiar da cooperação dos seus utilizadores, através da etiquetagem colaborativa, também para uma área tradicionalmente não indexada?

É desta forma que surge um estudo de caso sobre a etiquetagem colaborativa na Literatura, com o objetivo de aferir se a inclusão colaborativa de etiquetas em documentos literários enriqueceria o catálogo 2.0 das bibliotecas e, consequentemente, melhoraria o serviço de leitura prestado por estas instituições. Em específico, pretende-se avaliar as etiquetas atribuídas a obras literárias, verificando a ocorrência (ou não) dos aspetos problemáticos referidos pelos estudiosos de folksonomia e etiquetagem colaborativa; apontar possíveis vantagens e desvantagens da etiquetagem colaborativa de obras ficcionais; e concluir da pertinência (ou não) de um sistema de etiquetagem colaborativa para a Literatura, a incluir no catálogo 2.0 das bibliotecas. 


\section{Metodologia}

A fim de concluir da pertinência (ou não) de um processo de etiquetagem colaborativa para a Literatura, área tradicionalmente não indexada, apresenta-se um estudo de caso, de caráter exploratório, que se detém na análise e avaliação de etiquetas atribuídas a obras literárias. Para tal, foi observada a plataforma LibraryThing ${ }^{5}(\mathrm{LT})$, que se identifica como um serviço online para ajudar pessoas a catalogar os seus livros com facilidade, onde a prática da etiquetagem colaborativa é uma constante. Foi eleita esta plataforma, uma vez que comporta a funcionalidade LibraryThing for Libraries já incorporada por algumas bibliotecas nos seus catálogos, como dão conta alguns estudos. Rolla (2009) afirma que algumas bibliotecas já começaram a experimentar maneiras de incorporar etiquetas e outros conteúdos fornecidos pelos utilizadores em catálogos. Leitão (2009) refere que 238 bibliotecas em todo o mundo, maioritariamente norte-americanas, usam os serviços de LibraryThing for Libraries.

Kakali e Papatheodorou (2010) asseguram que o recente add-on $O P A C$, LibraryThing for Libraries, oferece às bibliotecas funcionalidades de pesquisa alternativas e enriquece os seus registos de catálogo. A isto acresce o facto de esta plataforma já ter sido utilizada em outras investigações, tendo sido obtidos resultados muito consistentes (ROLLA, 2009; ZUBIAGA et al., 2012).

Posteriormente, foi selecionado um bem conhecido escritor português, um clássico com obras em domínio público. Optou-se por Almeida Garrett, uma vez que já existe uma biblioteca digital com o seu nome, disponibilizada pela Biblioteca Nacional de Portugal ${ }^{6}$. Na segunda semana de janeiro de 2016, apurou-se a presença de 35 obras literárias da autoria de Garrett, incluídas na plataforma LT por utilizadores aí registados, e elaborou-se uma tabela com os dados da etiquetagem colaborativa obtida.

${ }^{5}$ Disponível em: <https://www.librarything.com/>. Acesso em: 5 jan. 2016.

${ }^{6}$ Disponível em: <http://purl.pt/96/1/obras/index.html>. Acesso em: 5 jan. 2016. 
Tabela 1 - Etiquetas atribuídas a 35 obras literárias de Almeida Garrett 
Frei Luís de Sousa

Travels Is My Homeland

(Viagens na minha terra)
"D. Sebastião" (1) 12th grade (1) literatura do século XIX (1) Batalha (1) clássico (2) Arte e cultura clássicas (1) D-5 (1) dead (1) domínio espanhol (1) domínio. filipino (1) Drama (4) Ensino (1) Ficção (2) Garrett (6) histórico (1) História (1) Kindle (1) História da literatura em Portugal (8) Literatura. Teatro (3) Mais Complementos (1) Maria Cristina (1) Casamento (1) Mito (1) Romance (1) possuído (1) Patriotismo (1) peça (1) Play (2) Portugal (2) Português (1) lido (1) read for school (1) read it in the portuguese version (the original version) (1) Religião (1) Romance (2) romanticism literature (1) Secundario (1) SM (4) Espanha (1) SWM (1) séc. 19 (1) tearjerker (1) teatro séc. 19 (1) Teatro (15) a ler (3) Uni (1)

Século XIX (2) literatura do século XIX (1)_global_reads (1)_unesco_world_lit (1) algar (1) Almeida Garrett (1) Autobiografia (1) borrowed (1) CG PQ9000-9999 (1) clássico (2) Arte e cultura clássicas (1) club de lectura (1) crónica (1) D-5 (1) European (1) Ficção (4) Genre Narratif (1) goodreads (1) Kindle (1) Libro de viajes (1) Lingua Lusitana (1) Literatura de viagens (1) História da literatura em Portugal (9) Literatura Romântica (1) Literatura. Ficção (2) literature - 1840s (1) literatureIberian (1) Maria Cristina (1) Noruega (1) Romance (1) novela (2) Portugal (2) Português (2) portuguese fiction (2) prose-in-portuguese (1) Punto de interés (1) Romance (5) romance brasileiro (1) romance séc. 19 (1) romances (1) SM (2) sociedade séc XIX (1) séc. 19 (1) a ler (1) Top 20 (1) Tradução (1) Viagem (3) JLTRecs. Fic (1)

O Arco de Sant'ana

Falar Verdade a Mentir

Século XIX (1) Ficção (2) História da literatura em Portugal (1) Literatura (1) Romance (1) Portugal (1) portuguese fiction (1) Romance (3) SM (1)

$9^{\circ}$ ano (1) Comédia (1) Maria Cristina Rocha (1) sátira sociedade portuguesa (1) Texto dramático (1) Teatro (1)

Folhas caídas

Camões

Frei Luís de Sousa - Um Auto de Gil Vicente

Um Auto de Gil Vicente

Obras completas de Almeida

Garrett

O alfageme de Santarém

D. Branca

A Moira Encantada

Discursos Parlamentares.

Colecção Saber.

Romanceiro II

VIAGENS NA MINHA

TERRA VOL I, $2^{a}$ edição

Poetas do Amor

VIAGENS NA MINHA

TERRA VOL II, $2^{a}$ edição

Magriço ou os doze de

Inglaterra

Obras Litterarias, Versos:

Camões / Dona Branca /

Lyrica...

Frei Luis De Sousa

Flores sem fructo

"A Nau Catrineta"

theatro do visconde de

almeida-garrett: a sobrinha

do marquez, as...

O roubo das Sabinas

Teatro e narrativa. Un "Auto"

di Gil Vicente. Il Romeo. La

fanciulla di... literatura do século XIX (1) clássico (1) História da literatura em Portugal (2)

Literatura. Poesia (1) Poesia de Portugal (1) Poesia (4) Romantismo (1)

Foreign literature (1) História da literatura em Portugal (1) principal k v (1)

D-5 (1) SM (1) Teatro (1)

\section{[Sem etiquetas]}

SM (1)

Garrett (1) História da literatura em Portugal (1) Teatro (1)

História da literatura em Portugal (1)

História da literatura em Portugal (1) Literatura. Poesia (1) poesia séc. 19 (1) Poesia

(1) séc. 19 (1)

discursos (1) Memorias (1)

D-5 (1) contos (1)

História da literatura em Portugal (1)

História da literatura em Portugal (1)

História da literatura em Portugal (1)

\section{[Sem etiquetas]}

[Sem etiquetas]

\section{[Sem etiquetas]}

História da literatura em Portugal (1) Poesia (1)

Maria Cristina Rocha (1)

Teatro (1)

Ensaio (1) Garrett (1) Poesia (1)

Literatura da Espanha (1) 


\begin{tabular}{|c|c|}
\hline Romanceiro & [Sem etiquetas] \\
\hline Lírica completa & Poesia de Portugal (1) Poesia (1) \\
\hline Romanceiro III & D-5 (1) contos (1) \\
\hline $\begin{array}{l}\text { Apontamentos Europa- } \\
\text { América Explicam "Frei Luís } \\
\text { de Sousa" }\end{array}$ & [Sem etiquetas] \\
\hline Folhas caidas e $3.55 \mathrm{~m}$ fruto & [Sem etiquetas] \\
\hline CatÄao & Teatro (1) \\
\hline Narrativas e lendas & História da literatura em Portugal (1) contos (1) \\
\hline $\begin{array}{l}\text { Cartas de Amor à } \\
\text { Viscondessa da Luz }\end{array}$ & arte epistolar (1) cartas (1) História da literatura em Portugal (1) \\
\hline $\begin{array}{l}\text { Viagem a minha terra } \\
\text { (Coleção Obras imortais da } \\
\text { nossa literatura, Vol.... }\end{array}$ & [Sem etiquetas] \\
\hline $\begin{array}{l}\text { O retrato de Venus e estudos } \\
\text { de historia litterÂaria }\end{array}$ & [Sem etiquetas] \\
\hline
\end{tabular}

Fonte: LIBRARYTHING (2016).

Após uma leitura global dos resultados, foram analisadas em pormenor as etiquetas das cinco obras literárias mais etiquetadas, a saber "Frei Luís de Sousa", a tradução inglesa de "Viagens na minha terra", "O arco de Sant'Ana", "Falar verdade a mentir" e "Folhas caídas". Este processo teve como pano de fundo os aspetos problemáticos e os proveitos apontados pelos investigadores da área da folksonomia e etiquetagem colaborativa. A verificação do conteúdo das etiquetas contou com o auxílio de uma professora de Português e Literatura Portuguesa. Os resultados da análise pormenorizada foram agrupados em três domínios (erro, ambiguidade e repetição) e apresentam-se em três correspondentes tabelas, sendo acompanhados de algumas considerações e conclusões de âmbito qualitativo.

\section{Discussão dos resultados}

Das 35 obras de Garrett constantes na LT, constatou-se que dez se encontram repetidas, por se encontrarem agrupadas, em volumes, em diferentes línguas ou com diferenças gráficas (letra e acentuação). Verificou-se que nove obras não se encontram etiquetadas (sem correspondência direta à repetição das mesmas), que duas apresentam grande quantidade de etiquetas e que 24 surgem, em média arredondada, com três etiquetas, numa quantidade variável entre uma e nove etiquetas; a média total arredondada é de quatro etiquetas e meia por obra literária. Estes resultados estão um pouco abaixo da média apresentada por Leitão (2009), que aponta sete a oito etiquetas por livro, no entanto muito em linha com González (2009) que refere a falta da exaustividade de alguns etiquetados e a profusão em outros. Leitão (2009, p. 130) explica este resultado com a Lei do Poder: "O número de palavras-chave em LT por cada obra parece seguir a Lei de Poder, o que se fica a dever ao facto de o número de palavras-chave atribuídas em cada livro reflectir, até um determinado ponto, a popularidade da obra". Esta circunstância parece ajustar-se, uma vez que as duas obras 
profusamente etiquetadas serão talvez as mais conhecidas de Almeida Garrett.

Em cada etiqueta verificou-se um número variável de palavras, com diferentes métodos de separação, a saber, ausência de espaço ("goodreads"), espaço em branco ("Top 20"), ponto final e espaço ("Literatura. Ficção"), traço ("_global_reads") e hífen ("literatureIberian"). Outra circunstância verificada prende-se com a variedade e versatilidade das etiquetas analisadas, mais concretamente com o diferente tipo de informação que elas comportam. Ocorrências do facto foram já abordadas por Yunta (2009), que refere que a terminologia utilizada na etiquetagem colaborativa é muito versátil, pois pode referir-se não só à descrição do conteúdo, mas também a aspetos subjetivos, a atributos ou a elementos do contexto. De facto, foram encontradas etiquetas com: descrição do conteúdo das obras literárias - "domínio. Filipino", "sátira à sociedade portuguesa", "mito"; aspetos subjetivos "Top 20", "a ler", "tearjerker"; atributos - "Literatura de viagens", "comédia", "Tradução"; e elementos do contexto - "ensino", "read for school", "Romantismo".

A generalidade da literatura que aborda questões relacionadas com etiquetagem colaborativa aponta diversos casos passíveis de originar problemas de revocação e de precisão. Da recolha efetuada, reúnem-se as ocorrências em três grupos, consoante o tipo de informação:

1) informação incorreta: quer quanto ao conteúdo, quer quanto à forma (erros ortográficos e tipográficos);

2) informação ambígua: consequência de polissemia, homonímia, sinonímia ou equivalência linguísticas; do uso de sinais, símbolos, mnemónicas e hápax; de etiquetas egoístas, amigas e populistas ${ }^{7}$;

3) informação repetida: através do uso de letras maiúsculas/minúsculas; de formas compostas e número/ordem variável de palavras; de abreviaturas e abreviações; de siglas e acrónimos; de outro idioma; de flexão vocabular (família de palavras) e morfológica (género, número, grau, pessoa e tempo); de linguagem mista (verbal e numeral).

Com base neste enquadramento, analisaram-se as etiquetas das cinco obras de Garrett mais etiquetadas no LT e os resultados apresentam-se nas tabelas que se seguem. Para efeitos deste estudo, na elaboração das tabelas, foram agrupados itens similares e, clarifica-se, uma etiqueta poderá estar incluída em vários itens.

Tabela 2 - Informação correta e incorreta

\begin{tabular}{|c|c|c|c|}
\hline Obra & Total de & Etiquetas & Etiquetas com informação incorreta \\
\hline
\end{tabular}




\begin{tabular}{l|c|c|c|c|c}
\hline \multicolumn{1}{c|}{ Literária } & etiquetas & $\begin{array}{c}\text { com } \\
\text { informação } \\
\text { correta }\end{array}$ & Conteúdo & \multicolumn{2}{|c}{ Forma } \\
\cline { 5 - 6 } & & 28 & 2 & 1 & $\begin{array}{c}\text { Erro } \\
\text { Ortográfico }\end{array}$ \\
\hline $\begin{array}{l}\text { Frei Luís de } \\
\text { Sousa }\end{array}$ & 46 & 28 & 5 & 1 & 0 \\
\hline $\begin{array}{l}\text { Travels Is My } \\
\text { Homeland } \\
\text { trad. de Viagens } \\
\text { na minha terra })\end{array}$ & 48 & 8 & 0 & 0 & 0 \\
\hline $\begin{array}{l}\text { OArco de } \\
\text { Sant'ana }\end{array}$ & 9 & 4 & 1 & 0 & 0 \\
\hline $\begin{array}{l}\text { Falar Verdade a } \\
\text { Mentir }\end{array}$ & 6 & 7 & 0 & 0 & 0 \\
\hline Folhas caídas & 7 & & & 0 \\
\hline
\end{tabular}

Fonte: LIBRARYTHING (2016).

Entende-se que informação correta é toda aquela considerada útil para o conhecimento da obra e que permita uma pesquisa eficiente (por exemplo, "domínio. filipino", referindo-se o período temporal em que se desenrola a ação). A percentagem de resultados corretos situa-se entre $58 \%$ e $100 \%$, números em linha com os estudos referidos por Kakali e Papatheodorou (2010), onde se concluiu que uma grande quantidade de etiquetas é precisa e confiável. Também a análise às três etiquetas mais utilizadas nas obras profusamente etiquetadas mostrou que estas contêm apenas informação correta.

Informação incorreta será aquela que conduz a erros sobre o conhecimento da obra e prejudica a pesquisa efetuada por um utilizador (por exemplo, "romance brasileiro" em vez de romance português) e a percentagem de resultados é de $0 \%$ a $10 \%$ no conteúdo e de $0 \%$ a $2 \%$ na forma, correspondendo esta apenas a erros de acentuação (por exemplo, "secundario").

Tabela 3 - Informação ambígua

\begin{tabular}{|c|c|c|c|c|c|c|c|c|}
\hline \multirow[b]{2}{*}{$\begin{array}{c}\text { Obra } \\
\text { Literária }\end{array}$} & \multirow[b]{2}{*}{$\begin{array}{l}\text { Total de } \\
\text { Etiquetas }\end{array}$} & \multicolumn{7}{|c|}{ Etiquetas com informação ambígua } \\
\hline & & $\begin{array}{c}\text { Polissemia } \\
\text { Homonímia }\end{array}$ & $\begin{array}{c}\text { Sinonímia } \\
\text { Equivalência }\end{array}$ & $\begin{array}{c}\text { Sinal } \\
\text { Símbolo }\end{array}$ & Mnemónica & $\begin{array}{c}\text { Hápax } \\
\text { Etiqueta } \\
\text { egoísta }\end{array}$ & $\begin{array}{l}\text { Etiqueta } \\
\text { Populista }\end{array}$ & $\begin{array}{c}\text { Sigla } \\
\text { Acrónimo }\end{array}$ \\
\hline $\begin{array}{c}\text { Frei Luís de } \\
\text { Sousa } \\
\end{array}$ & 46 & 2 & 1 & 0 & 0 & 9 & 2 & 2 \\
\hline $\begin{array}{l}\text { Travels Is My } \\
\text { Homeland } \\
\text { (trad. de } \\
\text { Viagens na } \\
\text { minha terra) }\end{array}$ & 48 & 2 & 2 & 1 & 0 & 12 & 3 & 0 \\
\hline $\begin{array}{l}\text { OArco de } \\
\text { Sant'ana }\end{array}$ & 9 & 1 & 0 & 0 & 0 & 1 & 0 & 0 \\
\hline $\begin{array}{c}\text { Falar } \\
\text { Verdade a } \\
\text { Mentir }\end{array}$ & 6 & 0 & 1 & 0 & 0 & 1 & 0 & 0 \\
\hline Folhas caídas & 7 & 0 & 0 & 0 & 0 & 0 & 0 & 0 \\
\hline
\end{tabular}

Considera-se que siglas e acrónimos são geradores de informação repetida, porém, neste estudo, surgem em informação ambígua, pois os casos registados enquadram-se neste âmbito. Clarifica-se o caso da palavra "Romance" que, embora registada com exata forma gráfica, surge 
duas vezes na mesma obra, tendo sido assumido no item polissemia/homonímia. Nesta tabela, não foi incluído o item etiqueta amiga, uma vez que não é possível o acesso à terminologia própria dos grupos, desconhecida para os elementos que lhes são exteriores. Assim, muito possivelmente, algumas etiquetas amigas terão sido consideradas egoístas, o que, em parte, poderá explicar o número de ocorrências nesta coluna. As palavras egoístas encerram forte valor pessoal para os utilizadores, porém, na perspetiva da biblioteca, podem criar confusão, não sendo uma informação útil e não acrescentando valor no acesso ao documento (ROLLA, 2009). Contudo, há registo de estudos que concluem que as etiquetas para uso pessoal constituem uma percentagem significativa (KAKALI; PAPATHEODOROU, 2010), o que se poderá confirmar também com os valores deste estudo: $0 \%$ a $25 \%$. Todos os restantes casos de ambiguidade registam percentagens inferiores a $6,5 \%$, sendo de assinalar os casos residuais de polissemia e sinonímia, antagonicamente muito referidos na literatura sobre etiquetagem colaborativa. No geral, os dados coadunam-se com os resultados obtidos por Spiteri (2007), em que as etiquetas ambíguas ou inconsistentes representam menos de um quarto das etiquetas totais.

Tabela 4 - Informação repetida

\begin{tabular}{c|c|c|c|c|c|c|c|c}
\hline \multirow{2}{*}{$\begin{array}{c}\text { Obra } \\
\text { Literária }\end{array}$} & $\begin{array}{c}\text { Total de } \\
\text { etiquetas }\end{array}$ & $\begin{array}{c}\text { Maiúscula } \\
\text { Minúscula }\end{array}$ & $\begin{array}{c}\text { Forma } \\
\text { composta } \\
\text { Número/Ordem } \\
\text { Variável }\end{array}$ & $\begin{array}{c}\text { Abreviatura } \\
\text { Abreviação }\end{array}$ & $\begin{array}{c}\text { Outro } \\
\text { Idioma }\end{array}$ & $\begin{array}{c}\text { Flexão } \\
\text { vocabular }\end{array}$ & $\begin{array}{c}\text { Flexão } \\
\text { morfológica }\end{array}$ & $\begin{array}{c}\text { Linguagem } \\
\text { Mista }\end{array}$ \\
\hline $\begin{array}{c}\text { Frei Luís de } \\
\text { Sousa }\end{array}$ & 46 & 0 & 10 & 1 & 3 & 2 & 0 & 1 \\
\hline $\begin{array}{c}\text { Travels Is My } \\
\text { Homeland } \\
\text { trad. de } \\
\text { Viagens na } \\
\text { minha terra })\end{array}$ & 48 & 0 & 16 & 3 & 6 & 1 & 1 & 2 \\
\hline $\begin{array}{c}\text { O Arco de } \\
\text { Sant'ana }\end{array}$ & 9 & 0 & 2 & 0 & 1 & 0 & 0 & 0 \\
\hline $\begin{array}{c}\text { Falar Verdade } \\
\text { a Mentir }\end{array}$ & 6 & 0 & 1 & 0 & 0 & 0 & 0 & 0 \\
\hline Folhas caídas & 7 & 0 & 4 & 0 & 0 & 0 & 0 & 0 \\
\hline
\end{tabular}

Fonte: LIBRARYTHING (2016).

O número de palavras por etiqueta varia entre um e nove, sendo que a maioria das etiquetas é composta por apenas uma palavra. $O$ facto de esta plataforma permitir um número ilimitado de palavras ocasiona repetição de informação enquadrável em forma composta; veja-se o caso de "Folhas caídas" que, com poucas etiquetas, apresenta três vezes a informação literatura e poesia ("literatura do século XIX (1) clássico (1) História da literatura em Portugal (2) Literatura. Poesia (1) Poesia de Portugal (1) Poesia (4) Romantismo (1))". A abreviatura da palavra século é a mais comum, apresentando a forma séc., aliada à não uniformização da linguagem que ocorre mista em 19 e XIX. Registam-se três outros idiomas, sendo o inglês o mais recorrente, e as formas flexionadas apresentam números residuais. No geral e por arredondamento, conclui- 
se que a informação repetida é considerável, registando valores entre os $17 \%$ e os $33 \%$.

Avaliadas as etiquetas deste estudo de caso, na globalidade dos resultados, verifica-se a ocorrência dos aspetos problemáticos referidos pelos investigadores de etiquetagem colaborativa, apesar do predomínio de informação correta. Os valores percentuais de informação errada, ambígua ou repetida não se apresentam muito perturbadores da precisão e revocação e não podem ser considerados desvantagens substanciais. Ainda assim, em casos de etiquetas egoístas e de formas compostas, os números não são negligenciáveis e merecem ser alvo de práticas corretivas.

Desta feita, não se defende a incorporação dos dados do LT no catálogo 2.0 das bibliotecas para a área da Literatura e sim a inclusão de uma folksonomia assistida para utilizadores registados, que, mantendo um considerável grau de liberdade, Ihes atenue a subjetividade e lhes proporcione caminhos (por exemplo, tempo, espaço, género literário, tema, personagem, opinião...) e sugestões automáticas de etiquetas, com base nas constantes no sistema. Julga-se que será essencial a elaboração de um manual de procedimentos simples, que permita aos utilizadores uniformizar práticas e evitar os casos relatados de informação ambígua e repetida, especificamente etiquetas egoístas e formas compostas. Recomenda-se que seja definido um número máxima de palavras por etiqueta, bem como a sua forma de separação.

Kakali e Papatheodorou (2010) recordam que uma parte das etiquetas contém informação relacionada com autor e com assuntos de catálogo. No caso em estudo, encontram-se duas referências ao autor ("Garrett" e "Almeida Garrett"); não se poderá estabelecer uma comparação de assuntos por se tratar de uma área tradicionalmente ausente nos vocabulários controlados. Ainda assim, nas etiquetas analisadas, verificou-se a ocorrência de informação constante na classificação atribuída pela Biblioteca Nacional. Por exemplo, "Viagens na minha terra"8 apresenta CDU 821.134.3-31"18", o que poderá já incluir um pré-preenchimento na página de catálogo com as etiquetas literatura portuguesa, ficção, prosa narrativa, romance e Séc. XIX, uma prática que evitaria informação repetida, pois estes dados encontram-se incluídos no LT 23 vezes. Assim, o registo dos utilizadores no sistema, o manual de procedimentos, as sugestões automáticas e o pré-preenchimento da plataforma com algumas etiquetas apresentam-se como medidas de algum controlo que permitiriam a redução de informação ambígua ou repetida, no entanto a informação errada ou abusiva carece de verificação e correção de pessoal especializado e, deste ponto de vista, tal não fará reduzir significativamente o tempo de trabalho ou baixar custos associados.

Muito embora se registem proveitos, as práticas folksonómicas não pretendem ser a solução para os problemas de indexação. Guedes et al. (2011) reconhecem mesmo que se trata de um movimento polifónico, que

\footnotetext{
${ }^{8}$ Disponível em: <http://purl.pt/55>. Acesso em: 5 jan. 2016.
} 
não substituirá as taxonomias. Ainda assim, considera-se que o esforço de criação de uma folksonomia assistida será produtivo, uma vez que foram encontradas etiquetas com informações relevantes para um mais profundo conhecimento das obras em análise. No caso de "Frei Luís de Sousa", etiquetas como "domínio espanhol", "casamento", "mito" e "religião" atingem temáticas secundárias porém muito significativas, a exemplo do relatado por Rolla (2009) e Kakali e Papatheodorou (2010). Confirma-se, então, que a "criação colaborativa de produtos de informação constitui, sem dúvida, uma das vias através das quais a participação dos utilizadores pode resultar em novos conteúdos informativos" (LEITÃO, 2009 , p. 139). Yedid (2013) vai mais longe e afirma que a etiquetagem colaborativa pode resultar mais confiável do que aquela fornecida pelos autores e até mesmo pelos profissionais da informação, algo que não se pode confirmar ou desmentir à luz dos dados deste estudo. Certo é que foram encontradas etiquetas de opinião, não constantes em vocabulários controlados e fora da prática dos profissionais de informação, que poderão ter a vantagem de auxiliar os utilizadores do catálogo na pesquisa e na seleção de leituras.

De acordo com os resultados deste estudo de caso, defende-se que, mesmo no âmbito da Literatura, área tradicionalmente não indexada, se encontram vantagens na etiquetagem colaborativa e que será muito proveitoso levar os utilizadores do catálogo das bibliotecas a explicitarem o seu conhecimento e a colaborarem com os profissionais de informação. Do ponto de vista do utilizador, considera-se que este se identificaria como parte ativa e importante da instituição, tendo benefícios diretos na obtenção de um espaço pessoal, nas pesquisas e sugestões de leitura, na possível pertença a grupos ou comunidade de leitores, à semelhança do que acontece no LT. Ao interagir com uma plataforma que compreende a sua forma de pensar e de comunicar, o utilizador tenderia a sentir-se compreendido e respeitado e a frequentar mais os espaços da biblioteca, tanto o físico como o virtual. Do ponto de vista do profissional da informação, a etiquetagem colaborativa permitiria maior exaustividade e representação mais completa face à tradicional ausência de indexação, pela agregação de valor e pela garantia pragmática fornecida pelo utilizador, no sentido que Ihe atribui Gracioso (2010). Ademais, esta será a melhor forma de, em tempo útil, se tratar a grande quantidade de documentos ficcionais da classe 8 nas bibliotecas, pois tal seria muito difícil de levar a cabo com os atuais recursos humanos e financeiros. Do ponto de vista da ciência, considera-se que o todo é mais do que a soma das partes e que a etiquetagem colaborativa com folksonomia assistida em Literatura permitiria aproximar o conhecimento dos utilizadores, quer pela linguagem quer pelo conteúdo, e enriquecê-lo com valor acrescentado. Portadora de um significado coletivo, não restam dúvidas de que a etiquetagem colaborativa da Literatura se apresentaria como um pertinente modelo de construção conjunta de conhecimento.

\section{Conclusões}


Com o advento da web 2.0, impõe-se aos serviços de informação e documentação um conjunto de práticas provenientes da folksonomia, entre elas a atribuição de etiquetas por produtores e consumidores de recursos online. A etiquetagem colaborativa é uma prática vulgarizada em diversas plataformas, porém não é habitual no catálogo das bibliotecas, muito provavelmente pelo seu caráter livre, ilimitado e descontrolado. Tais atributos não são do agrado dos sistemas organizados e hierarquizados de informação, no entanto é incontornável o valor agregado na relação informação-prosumidor e o contributo desta inteligência coletiva para o conhecimento.

Ao longo dos últimos anos foram desenvolvidos estudos que revelam que algumas bibliotecas, principalmente nos Estados Unidos da América, têm já implementado um catálogo 2.0 e beneficiam da colaboração dos seus utilizadores em diversas áreas do saber, contudo não há conhecimento de trabalhos na área da Literatura, tradicionalmente não indexada. Assim, recorrendo aos dados da plataforma LibraryThing, realizou-se um estudo de caso em obras literárias de Almeida Garrett, com o intuito de verificar se a etiquetagem colaborativa seria um fator de enriquecimento do catálogo de uma biblioteca e melhoraria o serviço prestado por esta instituição.

Concluiu-se que o catálogo da biblioteca poderá enriquecer-se com a cooperação dos seus utilizadores para etiquetar obras literárias ficcionais, com proveitos para os próprios, para o profissional da informação e para 0 conhecimento coletivo, sendo pertinente a etiquetagem colaborativa na Literatura. À semelhança do relatado em estudos anteriores e em diferentes áreas de saber, registou-se a ocorrência de aspetos problemáticos, que poderão ser ultrapassados mediante recurso a uma folksonomia assistida. Com alguma mediação no controlo/liberdade, constatou-se que é benéfica a cooperação entre utilizadores do catálogo e profissionais da informação, em especial para as áreas tradicionalmente não indexadas, e necessário o caminho híbrido nas bibliotecas, sendo este uma forma de melhorar o serviço de leitura prestado por estas instituições.

No paradigma informacional do momento, é urgente que as bibliotecas usufruam da cultura participativa, como recurso e como forma de se aproximar do seu público. Assim, o modelo folksonómico de etiquetagem colaborativa em catálogo 2.0 deverá deixar de apresentar-se como um desafio para os profissionais da informação e constituir uma prática generalizada nas bibliotecas, tendo proveitos e pertinência no domínio da Literatura.

Este trabalho encontra limitações no número reduzido de obras profusamente etiquetadas, porém revela alguma originalidade ao sugerir a inclusão generalizada de um sistema de etiquetagem colaborativa para uma área tradicionalmente não indexada. Considera-se pertinente aprofundar o conhecimento sobre esta temática e sugerem-se estudos futuros sobre a relação entre as bibliotecas e os seus utilizadores através 
das ferramentas da web 2.0, mais concretamente sobre o como suscitar e manter uma participação de qualidade.

\section{Referências}

BLATTMANN, U.; SILVA, F. Colaboração e interação na web 2.0 e biblioteca 2.0. Revista ACB: Biblioteconomia em Santa Catarina, v. 12, n. 2, p. 191-215, 2007. Disponível em: <http://revista.acbsc.org.br/racb/article/view/530>. Acesso em: $30 \mathrm{dez}$. 2015.

CAÑADA, J. Tipologías y estilos en el etiquetado social. 2008. Disponível em:

<http://web.archive.org/web/20111110154628/http://www.terremoto.ne t/tipologias-y-estlos-en-el-etiquetado-social/>. Acesso em: 10 jan. 2016

CATARINO, M. E.; BAPTISTA, A. A. Folksonomias: características das etiquetas na descrição de recursos da Web. Informação \& Informação, v. 14, p. 46-67, 2009. Disponível em: <http://www.uel.br/revistas/uel/index.php/informacao/article/view/3234

$>$. Acesso em: 14 jan. 2016.

CHOI, O.; JUNG, H.; MOON, S. Security techniques for prevention of rank manipulation in social tagging services including robotic domains. The Scientific World Journal, v. 2014, p. 1-10, 2014. Disponível em: <http://www.hindawi.com/journals/tswj/2014/832638/>. Acesso em: 30 dez. 2015.

CHUA, A. Y. K.; GOH, D. H. A study of web 2.0 applications in library websites. Library \& Information Science Research, v. 32, n. 3, p. 203-211, 2010. Disponível em: <http://www.sciencedirect.com/science/article/pii/S0740818810000307>. Acesso em: 14 jan. 2016.

COELHO, V. Bagunça informacional na web: folksonomia como alternativa aos métodos tradicionais de organização da informação. Anais do Encontro Virtual de Documentação em Software Livre e Congresso Internacional de Linguagem e Tecnologia Online, v. 4, n. 1, p. 1-5, 2015. Disponível em: <http://www.periodicos.letras.ufmg.br/index.php/anais linguagem tecnol ogia/article/view/8476>. Acesso em: 30 dez. 2015.

FREIXA-FONT, P. Patrimonio fotográfico y web 2.0: la experiencia Flickr The Commons. El profesional de la información, v. 20, n. 4, p. 432-438, 2011. Disponível

em: <https://dialnet.unirioja.es/servlet/articulo?codigo $=3743517>$. Acesso em: 19 dez. 2015.

GONZÁLEZ, O. Folcsonomías: el valor agregado de la indizacion social en el web. Acimed, v. 20, n. 3, p. 82-91, 2009. Disponível em: <http://www.imbiomed.com.mx/1/1/articulos.php?method=showDetail\&i d articulo=65424\&id seccion=686\&id ejemplar=6569\&id revista $=51>$. Acesso em: 30 dez. 2015. GONZALEZ, J. A. Evolução ontológica das 
linguagens documentárias: relato de uma experiência de curso organizado conjuntamente para o DT / SIBI-USP e o PPGCI/ECA. InCID: Revista de Ciência da Informação e Documentação, v. 2, n. 1, p. 143-164, 2011. Disponível em: <http://www.revistas.usp.br/incid/article/view/42339>. Acesso em: 30 dez. 2015.

GOUVÊA, C.; LOH, S. Folksonomias: identificação de padrões na seleção de tags para descrever conteúdos. Revista Eletrônica de Sistemas de Informação, v. 11, n. 2, p. 1-8, 2007. Disponível em: <http://www.spell.org.br/documentos/download/26637>. Acesso em: 14 jan. 2016.

GRACIOSO, L. D. S. Parâmetros teóricos para elaboração de instrumentos pragmáticos de representação e organização da informação na Web: considerações preliminares sobre uma possível proposta metodológica. InCID: Revista de Ciência da Informação e Documentação, v. 1, n. 1, p. 138-158, $2010 . \quad$ Disponível em: <http://www.revistas.usp.br/incid/article/view/42310 $>$. Acesso em: 16 dez. 2015.

GUEDES, R. D. M. et al. Indexação social e pensamento dialógico: reflexões teóricas. Informação \& Informação, v. 16, n. 3, p. 40-59, 2011. Disponível

em: < http://www.uel.br/revistas/uel/index.php/informacao/article/view/10477 >. Acesso em: 30 dez. 2015.

KAKALI, C.; PAPATHEODOROU, C. Exploitation of folksonomies in subject analysis. Library and Information Science Research, v. 32, n. 3, p. 192202, 2010.2 Disponível em: <http://www.sciencedirect.com/science/article/pii/S0740818810000368 >. Acesso em: 19 dez. 2015.

LEITÃO, P. Conteúdo gerado pelos utilizadores: desafios para as bibliotecas. Cadernos $B A D$, v. 1/2, p. 113-150, 2009. Disponível em: <http://www.bad.pt/publicacoes/index.php/cadernos/article/view/756>.

Acesso em: 30 dez. 2015.

ROLLA, P. J. User tags versus subject headings can user-supplied data improve subject access to library collections? Library Resources \& Technical Services, v. 53, n. 3, p. 174-184, 2009. Disponível em: <https://journals.ala.org/Irts/article/view/5281/6428>. Acesso em: 9 fev. 2016.

SEGUNDO, J.; VIDOTTI, S. Rede de tags para recuperação da informação no contexto da representação iterativa. InCID: Revista de Ciência da Informação e Documentação, v. 2, n. 1, p. 86-109, 2011. Disponível em: <http://www.revistas.usp.br/incid/article/view/42336>. Acesso em: 14 jan. 2016.

SPITERI, L. F. The structure and form of folksonomy tags: the road to the public library catalog. Information technology and libraries, v. 26, n. 3, p. 13-25, 2007. Disponível em: 
<http://ejournals.bc.edu/ojs/index.php/ital/article/view/3272/2885 > . Acesso em: 14 jan. 2016.

JUÁREZ URQUIJO, F. La biblioteca pública, un usuario más de la web 2.0. In: CONGRESO NACIONAL DE BIBLIOTECAS PÚBLICAS, 3., 2006, Murcia. Anales... Murcia (España), 2006. Disponível em: <http://eprints.rclis.org/3803/>. Acesso em: 14 jan. 2016.

WAL, T. V. Folksonomy. 2007. Disponível em: <http://vanderwal. net/folksonomy.html.>. Acesso em: $12 \mathrm{dez} .2015$.

YEDID, N. Introducción a las folksonomías: definición, caracteristicas y diferencias con los modelos tradicionales de indización. Información, Cultura Y Sociedad, v. 29, p. 13-26, 2013. Disponível em: $<$ http://revistascientificas.filo.uba.ar/index.php/ICS/article/view/673>. Acesso em 13 dez. 2015.

YUNTA, L. R. Etiquetado libre frente a lenguajes documentales: aportaciones en el ambito de biblioteconomia y documentacion. Actas del IX Congreso ISKO-España, v. 2, p. 832-845, 2009. Disponível em: <http://hdl.handle.net/10261/12295>. Acesso em: 30 dez. 2015.

ZUBIAGA, A. et al. Analyzing tag distributions in folksonomies for resource classification. 2012.

p. 1-12.

Disponível

em: <http://arxiv.org/abs/1202.5477v1>. Acesso em: 30 dez. 2015. 